\title{
New brawn, old brain: head transplant.
}

\author{
Manish Rohan James*
}

Department of Pharmacy, Jawaharlal Nehru Technological University, Hyderabad, Telangana, India

\begin{abstract}
As all of us are conscious that mind has continually been above brawn. Most of the time, I mean brain plays an important and a chief position in survival of a species (exceedingly evolved). It's only the brain that makes a creature. If a creature is able to continue to exist tactically and intellectually and is able to modify itself to the outside surroundings that adjustments daily and other creatures or other brains I say. A body is not anything without a mind. We have substitutes for the whole thing like, A pacemaker for Heart, Prosthetic limbs, Dialysis for kidneys. Eye transplantation's, Liver Transplants and many others. And humans now days are seeking to programme the baby. Which approach they could design their fetus the way they choice. Through Gene Editing tech. But, the brain can neither be replaced nor transplanted. According to me Brain is lifestyles. It shops the attention, the reminiscences and the most vital aspect is the sub-conscious part of the mind. Without which it's hard to do even a minute challenge or work. In this text I'd want to proportion my views on brain transplantation.
\end{abstract}

Keywords: Brain, Neural system, Immune system

Accepted on February 10, 2018

\section{Introduction}

It goes like this, what is the need of brain transplantation in the first place? We have some cases when a person has a brain which is working unto great potentials. But has a body which is weak or incompatible to his brain [1]. Or maybe sometimes there is a case where a person's death occurred because of kidney failure or heart failure or some other reason but the brain is perfectly alright. In such cases the person could be reanimated using this method [2]. Yes, there are many people out there that oppose this technique. Yet, there are many other that support it. Let's go deeper into this.

\section{How Do We Do This?}

Just in case we have a corpse [2]. That is brain dead and all other vital organs of the corpse are perfect. The body is selected for transplantation. It's not that we are making a Frankenstein here. It's for real as shown in the Figure 1. We are reanimating a dead person. This technique is yet in testing stages but this could be possible with the advancements in science and technology.

\section{So, This Is What Happened}

In early 20th century, a scientist, Robert J. White, had an idea about this thing i.e., head transplantation. So all he had to do is to transplant a head on a body which were never together. Sounds impossible right? But he made it possible for a meanwhile.

All he did was, he took the head of a dead monkey (brain was fully functional), monkey died of poisoning. Then he transplanted the head on the body of another monkey which was brain dead. He connected the neural system of the head to the neural system of the body. The monkey came back to life. It was quite normally behaving as it used to behave in its old body. But the monkey died after 19 days because of immune rejection [3]. The surgery was semi-successful. What if we implement this with humans, I mean we feel that human beings are superior and

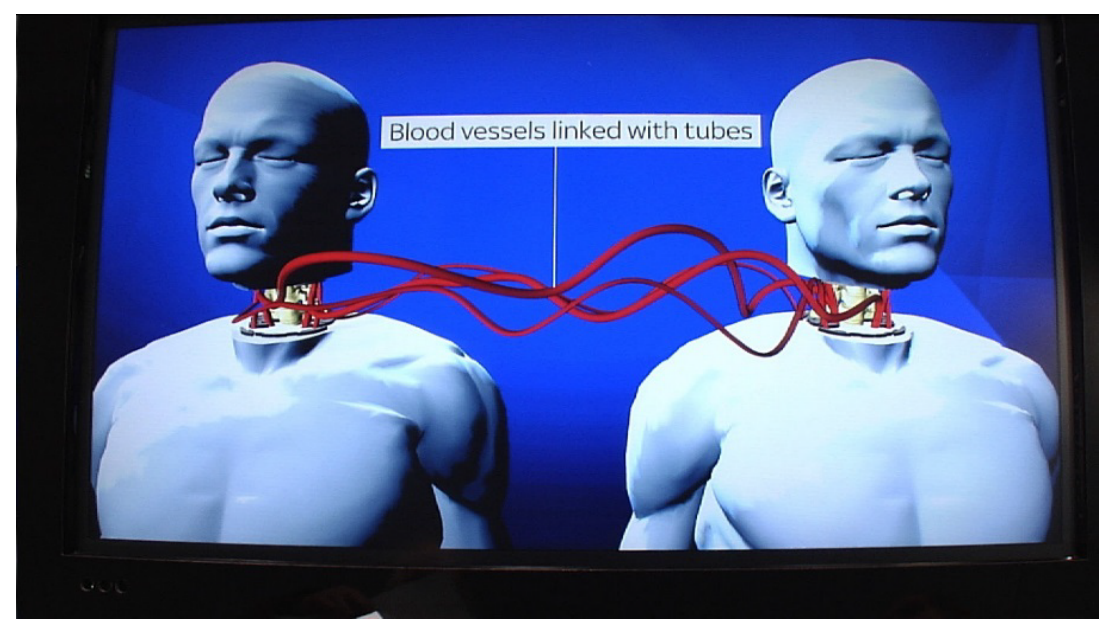

Figure 1. Blood vessels are linked. 
their lives matter. So, why not. Yes, we do have some ethics that are against this. But I support this.

\section{Complexions}

- Supress the immune system, using immune suppressants. As we keep taking insulin to control diabetes, Immune suppressants have to be taken regularly or at least once a week. But, this is risky because when immunity is very low the person is more vulnerable to other outbound infections.

- When we do transplant a head on a body, the problem is the head has a different genetic code [4], and the body has some other genetic code. They get incompatible to each other. Which is again a big problem.

Then how do we do this. I have an idea, which seems quite impossible but I just want to give it a try. I call it Pseudo-Rebirth.

We are all aware that we have the following things:

- Unique personality

- Consciousness

- Logical and Rational intelligence

- Creativity

- Emotions

- Way we understand things

These are the things that make us. That define us. So what I sense is, every one of the things listed above are only neural sports like synapses, neurotransmitters [5], genes in Brain and so on. So why don't we strive to code every emotion, programme the things in line with our mind set? I experience it's feasible. And as soon as we're executed with coding the things. We can set up this software into a laptop that has a good deal extra capability than a splendid pc. Then the man or woman will honestly live alive at the same time as actually he's useless. Let me make this clear. Once a character of a person is installed in a pc. The person is likely to reincarnate in a digital fact. Yes, he won't be able to move, experience the bodily contact, smell or taste the things, no ADME, no respiratory. But he is alive. All he will want is strength to continue to exist. The character will be able to concentrate thru a microphone, talk via the audio system, assume thru CPU and all of it makes experience. This cannot be made feasible without the intersection of Optogenetics , Neurology, Computers, AI and Medicine. I desire to look this clearly occurring inside the destiny. This is due to the fact human beings price human beings and people want people. This article would possibly appear to be a script of a Sci-Fi film. But this could honestly be fate of humanity someday.

\section{Conclusion}

Each life matters to me. No matter what I don't want to let a person die. Biological Death is obvious. But digital life is something revolutionary. I just shared my idea. Research must be done. Advancements in the technology will let this thing happen for real one day. Consciousness could be captured, transferred, altered. If the real effort is put into this idea. Future is here.

\section{References}

1. Ren X, Sergio C. HEAVEN in the making: Between the rock (the academe) and a hard case (a head transplant). AJOB Neuroscience. 2017;8:200-5.

2. Barrangou R, Christophe F, Hélène $\mathrm{D}$, et al. CRISPR provides acquired resistance against viruses in prokaryotes. Science. 2007:1709-12.

3. Drukker M, Helena K, Gil K, et al. Human embryonic stem cells and their differentiated derivatives are less susceptible to immune rejection than adult cells. Stem Cells. 2006:221-9.

4. Crick Francis HC. The origin of the genetic code. J Mol Biol. 1968:367-79.

5. Snyder SH. Nitric oxide: first in a new class of neurotransmitters. Science. 1992:494-96.

\section{*Correspondence to:}

Manish Rohan James

Department of Pharmacy

Jawaharlal Nehru Technological University

Hyderabad

India

E-mail: manishjames2.mj@gmail.com 